\title{
Comprehensive Efficacy of the Dipeptidyl Peptidase 4 Inhibitor Alogliptin in Practical Clinical Settings: A Prospective Multi-Center Interventional Observational Study
}

\author{
Yosuke Takamiya $^{\mathrm{a}, \mathrm{c}}$, Kunihisa Kobayashi ${ }^{\mathrm{b}}$, Tadachika Kudo ${ }^{\mathrm{b}}$, Tetsu Okuda ${ }^{\mathrm{a}}$, Keisuke Okamura ${ }^{\mathrm{a}}$, \\ Kazuyuki Shirai ${ }^{\text {a }}$, Hidenori Urata ${ }^{\text {a }}$, on behalf of the Chikushi Cardiovascular \\ Research Network
}

\begin{abstract}
Background: This study aimed to verify the safety and efficacy, including glycemic control, of the selective dipeptidyl peptidase 4 inhibitor alogliptin in patients with type 2 diabetes.

Methods: This study used a multi-center, open-label, prospective observational design. Type 2 diabetes patients who were undergoing dietary therapy and/or exercise therapy alone without sufficient glycemic control (hemoglobin A1c $(\mathrm{HbA} 1 \mathrm{c}) \geq 6.5 \%$ and $<10 \%)$ were administered alogliptin ( $25 \mathrm{mg} /$ day). The long-term effects ( 6 and 12 months) on blood glucose, blood pressure, heart rate, body weight and lipids were assessed.

Results: A final 50 patients were included with a high prevalence of hypertension (77\%) and dyslipidemia (72\%), and a mean duration of diabetes of 4.5 years. Pre-treatment $\mathrm{HbAlc}$ was $7.5 \%$ and was significantly decreased at 6 and 12 months (6M: $6.4 \%, 12 \mathrm{M}$ : $6.2 \% ; \mathrm{P}<0.02$ vs. $0 \mathrm{M}$, respectively). Body weight, blood pressure and low-density lipoprotein cholesterol were significantly decreased by 6 months and maintained at 12 months. Triglycerides showed a significant decrease at 12 months. No significant differences were observed in HbAlc decrease for different grade of age, duration of diabetes, body mass index and renal function. The degree of decrease in $\mathrm{HbA1c}$ was most strongly correlated with pre-treatment $\mathrm{HbAlc}$. Adverse events were noted in three patients, with no serious outcomes.
\end{abstract}

Manuscript submitted May 19, 2020, accepted June 9, 2020

Published online June 25, 2020

aDepartment of Cardiovascular Diseases, Fukuoka University Chikushi Hospital, Chikushino, Japan

${ }^{b}$ Department of Endocrinology and Diabetes Mellitus, Fukuoka University Chikushi Hospital, Chikushino, Japan

${ }^{\mathrm{c} C o r r e s p o n d i n g ~ A u t h o r: ~ Y o s u k e ~ T a k a m i y a, ~ D e p a r t m e n t ~ o f ~ C a r d i o l o g y, ~ F u k u o-~}$ ka University School of Medicine, Fukuoka, Japan. Email: takamiya2011@ cis.fukuoka-u.ac.jp

doi: https://doi.org/10.14740/jocmr4224
Conclusion: The blood glucose-lowering effect and safety of alogliptin were demonstrated regardless of baseline $\mathrm{HbAlc}$, although its effect appeared stronger with higher pre-treatment HbA1c values. Additionally, alogliptin appears useful for managing atherosclerotic risk factors such as body weight and blood pressure.

Keywords: DPP-4 inhibitor; Alogliptin; type 2 diabetes; HbA1c

\section{Introduction}

Glycemic control is essential for patients with type 2 diabetes, with many epidemiological analyses demonstrating that good control lowers the risk of development or progression of microangiopathy or macroangiopathy [1-3]. Although there are no clear standards for how tight blood glucose control needs to be in order to suppress the development of complications, in Japan, evidence suggests that hemoglobin A1c (HbA1c) levels below $6.9 \%$ are mostly sufficient to prevent the development and progression of microangiopathy [4]. In contrast, macroangiopathy has a high risk of onset or progression, including from the stages of abnormal glucose tolerance (i.e., abnormally high blood glucose levels after meals). Therefore, the ideal goal of glycemic control is to correct fasting and postprandial hyperglycemia throughout the day without episodes of hyper or hypoglycemia, thereby normalizing $\mathrm{HbAlc}$ levels that serve as an indicator of average blood glucose values.

The prevalence of diabetes is rising notably, and general physicians are increasingly required to provide diabetic medical care, regardless of whether they are specialists or not. Diabetic drugs are therefore required to not only exert blood glucose-lowering actions but also demonstrate and maintain safety at levels higher than before. Previously, we reported on the blood glucose-lowering actions and safety of the dipeptidyl peptidase 4 (DPP-4) inhibitors sitagliptin and teneligliptin in clinical practice for community-treated patients $[5$, 6]. Alogliptin is an oral type 2 diabetes drug that, along with sitagliptin and teneligliptin, is classified as a DPP-4 inhibitor. 
In the present study, we prospectively examined the efficacy and safety of alogliptin treatment in practice in terms of blood glucose control over 12 months in patients who were receiving medical treatment with alogliptin. Additionally, this study also aimed to determine in what cases alogliptin may be highly useful considering the rate of improvement in blood glucose.

\section{Materials and Methods}

\section{Study design}

This study used a prospective, multi-center, interventional observational design. Patients with type 2 diabetes who visited the Outpatient Department of Fukuoka University Chikushi Hospital and medical centers registered with the Chikushi Cardiovascular Research Network (Chikushi-JRN) were enrolled in this study after obtaining informed consent.

Patients with type 2 diabetes who had not achieved sufficient control with dietary therapy and/or exercise therapy alone ( $\mathrm{HbA} 1 \mathrm{c} \geq 6.5 \%$ and $<10 \%$ ) during an observational period of over 1 month were started on alogliptin, and its efficacy and safety were examined at 6 and 12 months.

Primary endpoints were assessed at the time of treatment initiation and after 6 months and included the following: HbA1c level, blood pressure, lipids, heart rate, body weight and adverse events. Secondary endpoints were all cardiovascular events throughout the study period (hospitalization due to cardiovascular disease, development of cardiovascular disease and death). These data included the actual changes and rates of change in $\mathrm{HbAlc}$, blood pressure, heart rate and body weight measured at 0,6 and 12 months, as well as safety.

This study was conducted after obtaining approval from the Ethics Committee of Fukuoka University Chikushi Hospital (approval no: R11-013). All researchers involved in this clinical study carried out the study in accordance with the Declaration of Helsinki and its subsequent amendments.

\section{Exclusion criteria}

Exclusion criteria were as follows: patients with severe ketosis, diabetic coma or pre-coma, or type 1 diabetes; patients who have severe infection, have undergone or are scheduled to undergo surgery, or have serious trauma; patients who had a stroke or myocardial infarction in the past 3 months or developed other serious cardiovascular complications that required hospitalization; patients with renal dysfunction (serum creatinine $\geq 3.0 \mathrm{mg} / \mathrm{dL}$ ); patients with liver dysfunction (alanine transaminase (ALT) level $\geq 100 \mathrm{IU} / \mathrm{L}$ ); patients with cancer or serious diseases with poor prognoses; patients with a history of hypersensitivity to the components of alogliptin; and patients who were deemed unfit by the attending physician.

\section{Discontinuation criteria}

Discontinuation criteria were as follows: glycemic control remained poor even after administration of alogliptin; an excessive decrease in blood glucose was observed after administration of alogliptin; continuation of the study was considered difficult due to adverse events; medication compliance was notably poor (the number of times the drug was administered was $<75 \%$ or $\geq 120 \%$ ); and cases in which the physician judged it to be appropriate to discontinue the study due to other reasons.

\section{Statistical analysis}

Statistical analyses were performed at Fukuoka University using IBM SPSS Statistics 23 software. The $t$-test was performed to determine the significance of differences for variables with a normal distribution. In addition, Levene's test was used to assess the equality of variance, and Welch's test was employed if equal variance was not confirmed. If the data did not show a normal distribution, the Wilcoxon signed-rank test and the Mann-Whitney test were used. Successive changes were examined using repeated-measures analysis of variance.

Pearson's product correlation coefficients were used to test correlations, and partial correlation coefficients were added. Numerical results are expressed as the mean (standard deviation (SD)), median (interquartile range (IQR)), or frequency (\%). In all analyses, $\mathrm{P}<0.05$ was considered to indicate significance.

\section{Results}

From October 1, 2011 through July 5, 2012, 80 patients were enrolled. Of these, 20 patients were excluded, including three patients with adverse events, 13 patients who dropped out and four patients with insufficient effects. Adverse events included one case of liver dysfunction, one case of rash and one case of increased saliva secretion. In addition, 10 patients with missing $\mathrm{HbAlc}$ values were excluded, and data from 50 patients were included in the analysis (Fig. 1).

Table 1 shows the characteristics of patients and administered drugs. Patients had a high prevalence of hypertension (77\%) and dyslipidemia (72\%). The duration of diabetes was relatively short at 4.5 years, and $37 \%$ of patients were taking statins. The most frequently administered anti-hypertensive drugs were calcium channel blockers (48\%), followed by angiotensin II receptor blockers (38\%).

Table 2 shows changes in the main parameters from baseline. HbA1c (at initiation: 7.5\%) was significantly decreased at 6 months (HbA1c: $6.4 \%, \mathrm{P}<0.01$ vs. 0 month), and a further decrease was noted at 12 months (HbA1c: $6.2 \%, \mathrm{P}<0.01 \mathrm{vs}$. 0 month). A significant decrease in body weight was observed at 6 months, with this decrease maintained at 12 months. Systolic blood pressure (SBP) and diastolic blood pressure (DBP) were significantly lower at both 6 and 12 months. A significant decrease in triglycerides was observed continuously up to 12 months.

Table 3 shows the degree of decrease in blood glucose at 6 and 12 months by different grade of age, duration of diabetes, body mass index (BMI) and estimated glomerular filtration rate (eGFR). No particular associations were found between 


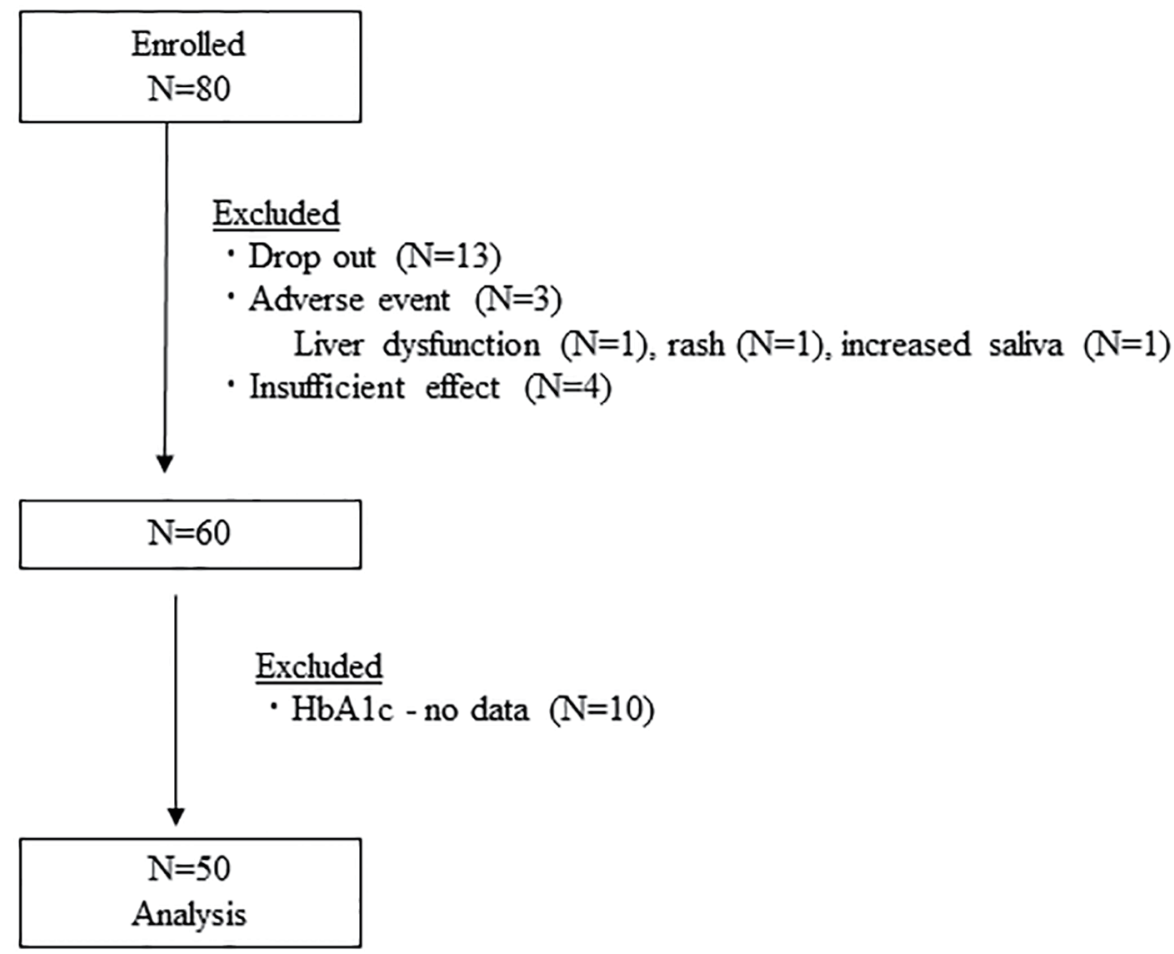

Figure 1. Flow diagram of study participants. HbA1c: hemoglobin A1c.

the blood glucose-lowering action and age, diabetic history, degree of obesity and renal function.

Table 4 shows the correlations between the change in $\mathrm{HbA} 1 \mathrm{c}$ at 6 and 12 months and each parameter. The degree of decrease in HbA1c at 6 and 12 months was correlated with baseline $\mathrm{HbA} 1 \mathrm{c}$ and SBP, with baseline HbAlc showing the strongest correlation.

Partial correlation coefficients between the degree of decrease in HbAlc at 6 and 12 months and baseline HbAlc and SBP were analyzed (Table 5). Even after eliminating the influence of baseline SBP, the correlation between baseline HbA1c and the degree HbA1c decrease remained strong. The significant correlation between baseline SBP and change in HbA1c disappeared after adjusting for baseline HbA1c.

\section{Discussion}

Major findings were as follows: 1) A significant decrease in HbA1c was observed continuously over 12 months. 2) No serious adverse events were reported. 3) SBP and DBP were both significantly decreased. 4) Significant decreases in body weight and triglycerides were observed over 12 months, and in particular, body weight was significantly lower at 12 months compared to 6 months. 5) Age, diabetic history, degree of obesity and renal function were not associated with blood glucoselowering action, with alogliptin. 6) The degree of decrease in $\mathrm{HbA} 1 \mathrm{c}$ showed a strong correlation only with pre-treatment $\mathrm{HbA1c}$ value.

Alogliptin significantly decreased HbAlc over 12 months while maintaining safety in patients with type 2 diabetes. Although some studies have reported on the short-term efficacy and safety of alogliptin, only a few reports have prospectively assessed its long-term efficacy and safety over 12 months. The present study used a multi-center design with 23 participating sites, roughly $82 \%$ of which were community-based clinics. Thus, this study is likely in line with real-world clinical practice showing results in community-treated patients.

After at least 1-month lifestyle modification, each physician judged to prescribe alogliptin based on inadequate glycemic control. The educational advice for lifestyle modification for each patient continued after the initiation of alogliptin, so that we could observe add-on effect of alogliptin in this study protocol.

A meta-analysis of 78 randomized trials [7] of DPP-4 inhibitors reported a mean degree of decrease in HbAlc of $0.74 \%$ (baseline HbA1c: $8 \%$ ). In the present study (baseline HbA1c: $7.6 \%$ ), a relatively high degree of decrease in HbA1c of $1.3 \%$ was observed at 12 months. There are two possible reasons for this. Compared to Europeans and Americans, people in Asian countries are more likely to achieve improvement in blood glucose with DPP-4 inhibitors [8]. Moreover, while alogliptin is more selective for DPP-4 and has a higher rate of inhibition compared to other DPP-4 inhibitors [9], the dosage of alogliptin is the same as that approved overseas. Therefore, the effects of alogliptin may have been more substantial compared to other DPP-4 inhibitors. We have previously reported the decrease in $\mathrm{HbA} 1 \mathrm{c}$ by teneligliptin $(7.5 \%$ at baseline vs. $0.9 \%$ at 6 months), as well as the amount of change in HbAlc due to sitagliptin $(7.5 \%$ at baseline vs. $0.6 \%$ at 24 months). 
Table 1. Patient Characteristics

\begin{tabular}{|c|c|}
\hline Characteristics & $\mathbf{N}(\%)$ \\
\hline $\mathrm{N}$ & 50 \\
\hline Mean age (SD), years & $64.2 \pm 11.7$ \\
\hline Male & $28(56)$ \\
\hline Duration, years & $4.3 \pm 3.8$ \\
\hline Body mass index, $\mathrm{kg} / \mathrm{m}^{2}$ & $26.0 \pm 4.7$ \\
\hline \multicolumn{2}{|l|}{ Clinical presentation } \\
\hline Hypertension & $37(74)$ \\
\hline Dyslipidemia & $35(70)$ \\
\hline Hyperuricemia & $6(12)$ \\
\hline Current smoking & $11(22)$ \\
\hline Current drinking & $29(48)$ \\
\hline Ischemic heart disease & $1(2)$ \\
\hline Previous stroke & $5(10)$ \\
\hline Diabetic retinopathy & $2(4)$ \\
\hline Diabetic nephropathy & $7(14)$ \\
\hline Diabetic neuropathy & $1(2)$ \\
\hline \multicolumn{2}{|l|}{ Medication } \\
\hline \multicolumn{2}{|l|}{ Anti-hypertensive drugs } \\
\hline Diuretic drugs & $8(16)$ \\
\hline Calcium channel blockers & $24(48)$ \\
\hline ACE inhibitors & $2(4)$ \\
\hline Angiotensin II receptor blockers & $19(38)$ \\
\hline Beta-blockers & $4(8)$ \\
\hline \multicolumn{2}{|l|}{ Anti-dyslipidemic drugs } \\
\hline Statin & $18(36)$ \\
\hline Fibrates & $1(2)$ \\
\hline Ezetimibe & $3(6)$ \\
\hline Anti-thrombotic agents & $3(6)$ \\
\hline
\end{tabular}

Data are the number (\%) or means \pm SD. SD: standard deviation; ACE: angiotensin-converting enzyme.

Both these decreases were lower compared to those of alogliptin, supporting the above statement.

Monnier et al reported that $\mathrm{HbAlc}$ of $\geq 8.5 \%$ mainly reflects fasting hyperglycemia, whereas HbAlc of $\leq 7.3 \%$ mainly reflects postprandial hyperglycemia [10]. Considering this premise, we performed an additional analysis by dividing baseline $\mathrm{HbA} 1 \mathrm{c}$ values into the following categories: HbA1c $\geq 8.5 \%, 8.5 \%>\mathrm{HbA} 1 \mathrm{c} \geq 7.3 \%$ and $\mathrm{HbAlc}<7.3 \%$ (data not shown). Significant decreases in HbAlc were observed in all three groups: 1) HbA1c $\geq 8.5 \%$ group $(\mathrm{N}=10)$ : HbA1c $10.0 \%$ (0M), 6.8\% (6M), 6.3\% (12M); 2) 8.5\% > HbA1c $\geq 7.3 \%$ group $(\mathrm{N}=10)$ : HbAlc $7.9 \%(0 \mathrm{M}), 6.8 \%(6 \mathrm{M}), 6.9 \%(12 \mathrm{M})$; and 3$)$ HbA1c $<7.3 \%$ group $(\mathrm{N}=30)$ : HbAlc 6.6\% (0M), 6.1\% (6M), $6.0 \%(12 \mathrm{M})(\mathrm{P}<0.01)$. Significant decreases were observed with treatment using alogliptin regardless of the pre-treatment HbA1c, suggesting the possibility that alogliptin could improve blood glucose from fasting to the postprandial state.

Adverse events were documented in three patients, and all patients recovered after discontinuing alogliptin. No serious adverse event was recorded, and in particular, no hypoglycemia or major adverse cardiovascular events (MACEs) were observed. In the present study, the number of non-diabetes specialists was high at $67 \%$ (cardiologists: $41 \%$, gastroenterologists: $16 \%$, surgeons: $8 \%$ and respiratory physicians: $2 \%$ ), further supporting our findings that alogliptin is an easy-to-use drug with high safety.

Correlations of the blood glucose-lowering action of alogliptin with various clinical factors were observed, and the strongest correlation was with baseline HbA1c. A previous study [7] also reported that DPP-4 inhibitors are particularly useful to improve blood glucose in patients with high pretreatment HbA1c. We have previously reported that baseline HbA1c was most strongly correlated with the degree of decrease in blood glucose for sitagliptin and teneligliptin $[5,6]$, and similar results were obtained in the present study. At face value, the simple reason that it is easier to obtain a decrease if the initial HbAlc value is high partially explains this. In addition, given that incretins promote insulin secretion in response to blood glucose, the higher the level of glucose that flows into pancreatic $\beta$ cells, the higher the secretion of insulin; hence, higher efficacy can be expected.

No significant correlation between baseline SBP and the amount of decrease in HbA1c was observed when the influence of baseline HbA1c was removed. Therefore, pre-treatment SBP is unlikely to be a predictor for blood glucose improvement. In addition, a study regarding sitagliptin found a correlation between the degree of decrease in HbA1c and low BMI and short disease duration. For teneligliptin, a correlation with younger age has been observed. In contrast, correlations with these factors (BMI, age, disease duration and eGFR) were not observed in the present study. Although the results of the present study, as well as those of previous studies, suggest that pre-treatment $\mathrm{HbAlc}$ could be established as a predictor of the usefulness of DPP-4 inhibitors, there are likely to be other factors that have yet to be clarified.

Notably, significant decreases in body weight $(-1.3 \mathrm{~kg})$, triglycerides $(-28 \mathrm{mg} / \mathrm{dL})$ and low-density lipoprotein cholesterol (LDL-C) $(-7 \mathrm{mg} / \mathrm{dL})$ were observed in this study after 12 months of alogliptin treatment in practical clinical settings. In general, DPP-4 inhibitors have not been reported to cause a change in body weight. Thus, the body weight-lowering action observed in the present study is possibly a specific action of alogliptin. In mice, alogliptin has been reported to significantly suppress an increase in visceral fat and hypertrophy of fat cells [11]. Hence, the underlying mechanism for the decrease in body weight was presumed to be an alogliptin-specific action on fat cells.

Previous studies have reported that DDP-4 inhibitors may improve total cholesterol and triglycerides compared to other oral hypoglycemic agents [12] and that alogliptin in particular lowers triglycerides and LDL-C [13]. As glucagon-like peptide-1 (GLP-1) suppresses chylomicron synthesis in the intestinal tract, this may be a potential mechanism by which DPP-4 inhibitors suppress chylomicron synthesis.

Nonetheless, there is a possibility that patients themselves might have reexamined their dietary life and exercise habits on joining the study, which might have caused or contributed to 
Table 2. Change in Parameters at 6 and 12 Months

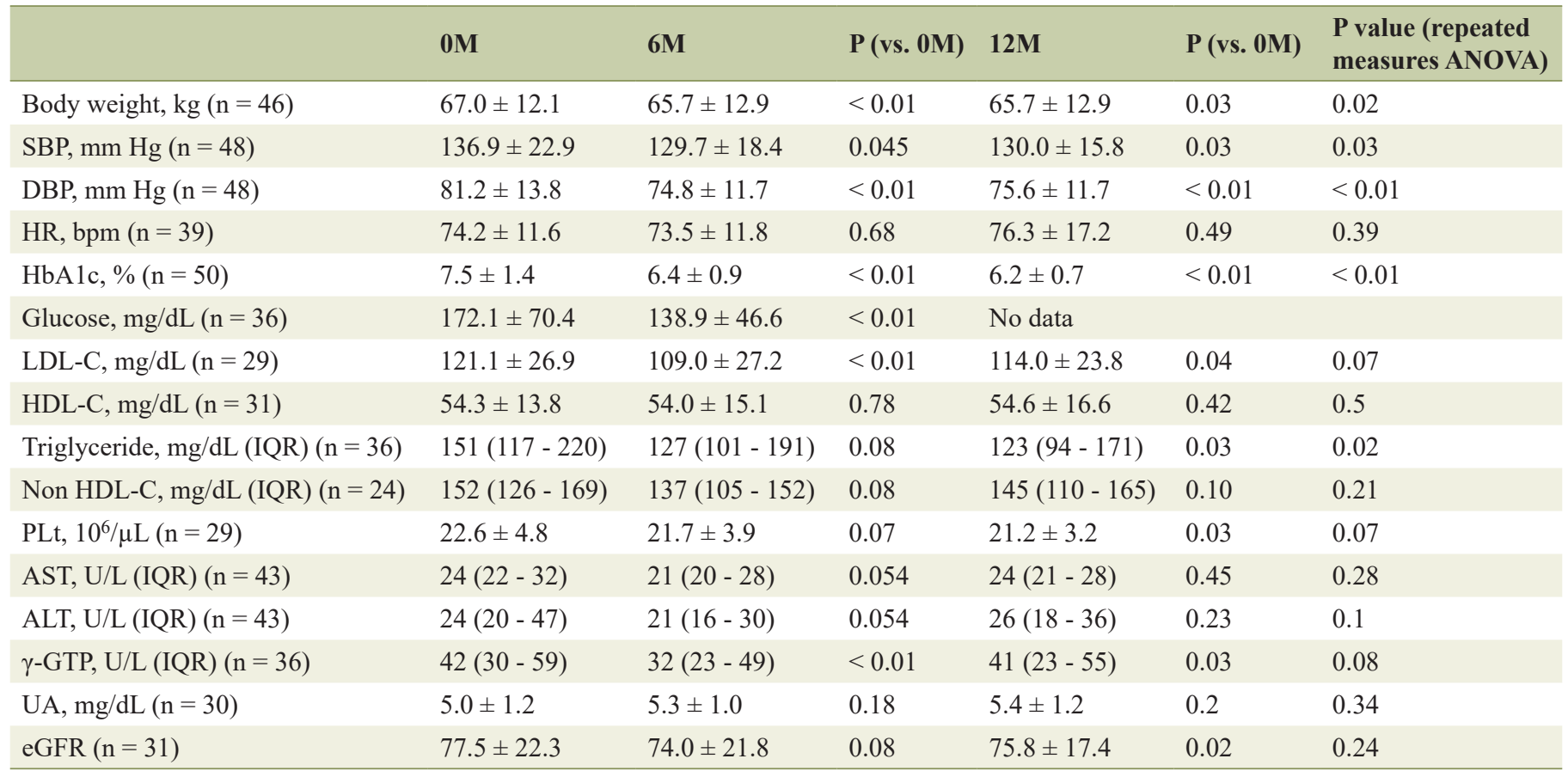

Data are the means \pm standard deviation or the medians (interquartile range (IQR)). $P$ values were obtained by the paired $t$-test. ANOVA: analysis of variance; SBP: systolic blood pressure; DBP: diastolic blood pressure; HR: heart rate; HbA1c: hemoglobin A1c; LDL-C: low-density lipoprotein cholesterol; HDL-C: high-density lipoprotein cholesterol; PLt: platelet; AST: aspartate transaminase; ALT: alanine transaminase; Y-GTP: gamma-glutamyl transpeptidase; UA: uric acid; eGFR: estimated glomerular filtration rate.

the decrease in body weight and improvement in blood pressure and lipids. However, further analysis (data not shown) showed no correlations between the degree of decrease in body weight and the lowering of triglycerides or lowering of LDLC. Therefore, the observed changes can most likely be attributed to the multifactorial effects of alogliptin.

In the present study, after 12 months of alogliptin admin- istration, decreases in SBP of $7 \mathrm{~mm} \mathrm{Hg}$ and DBP of $6 \mathrm{~mm}$ $\mathrm{Hg}$ were observed. A previous study in Japan has shown the presence of insulin resistance and hyperinsulinemia in patients with hypertension [14]. These conditions cause increases in sympathetic nerve activity and renin-angiotensin-aldosterone system activity, resulting in increased cardiac output due to reabsorption of $\mathrm{Na}$ and increased peripheral vascular resistance

Table 3. Change in $\mathrm{HbA} 1 \mathrm{c}$ at 6 and 12 Months According to the Different Age, Duration of Diabetes, BMI and Renal Function

\begin{tabular}{lll}
\hline & HbA1c $(\mathbf{6 M})-$ HbA1c $(\mathbf{0 M})$ & HbA1c $(\mathbf{1 2 M})-\mathbf{H b A 1 c}(\mathbf{0 M})$ \\
\hline Age $<65$ years $(\mathrm{n}=27)$ & -1.37 & -1.35 \\
Age $\geq 65$ years $(\mathrm{n}=23)$ & -0.91 & -1.10 \\
P value & 0.34 & 0.64 \\
Duration $<5$ years $(\mathrm{n}=27)$ & -1.20 & -1.20 \\
Duration $\geq 5$ years $(\mathrm{n}=19)$ & -1.19 & -1.41 \\
$\mathrm{P}$ & 0.99 & 0.61 \\
BMI $<25(\mathrm{n}=24)$ & -1.36 & -1.43 \\
BMI $\geq 25(\mathrm{n}=26)$ & -0.97 & -1.04 \\
$\mathrm{P}$ & 0.30 & 0.31 \\
eGFR $\geq 60(\mathrm{n}=30)$ & -1.07 & -1.09 \\
eGFR $<60(\mathrm{n}=7)$ & -0.79 & -0.92 \\
$\mathrm{P}$ & 0.53 & 0.71 \\
\hline
\end{tabular}

HbA1c: hemoglobin A1c; BMI: body mass index; eGFR: estimated glomerular filtration rate; 0M: 0 months (baseline); $6 \mathrm{M}$ : after 6 months of treatment; 12M: after 12 months of treatment. 
Table 4. Correlations of Various Factors With $\Delta \mathrm{HbA} 1 \mathrm{c}$ at 6 and 12 Months

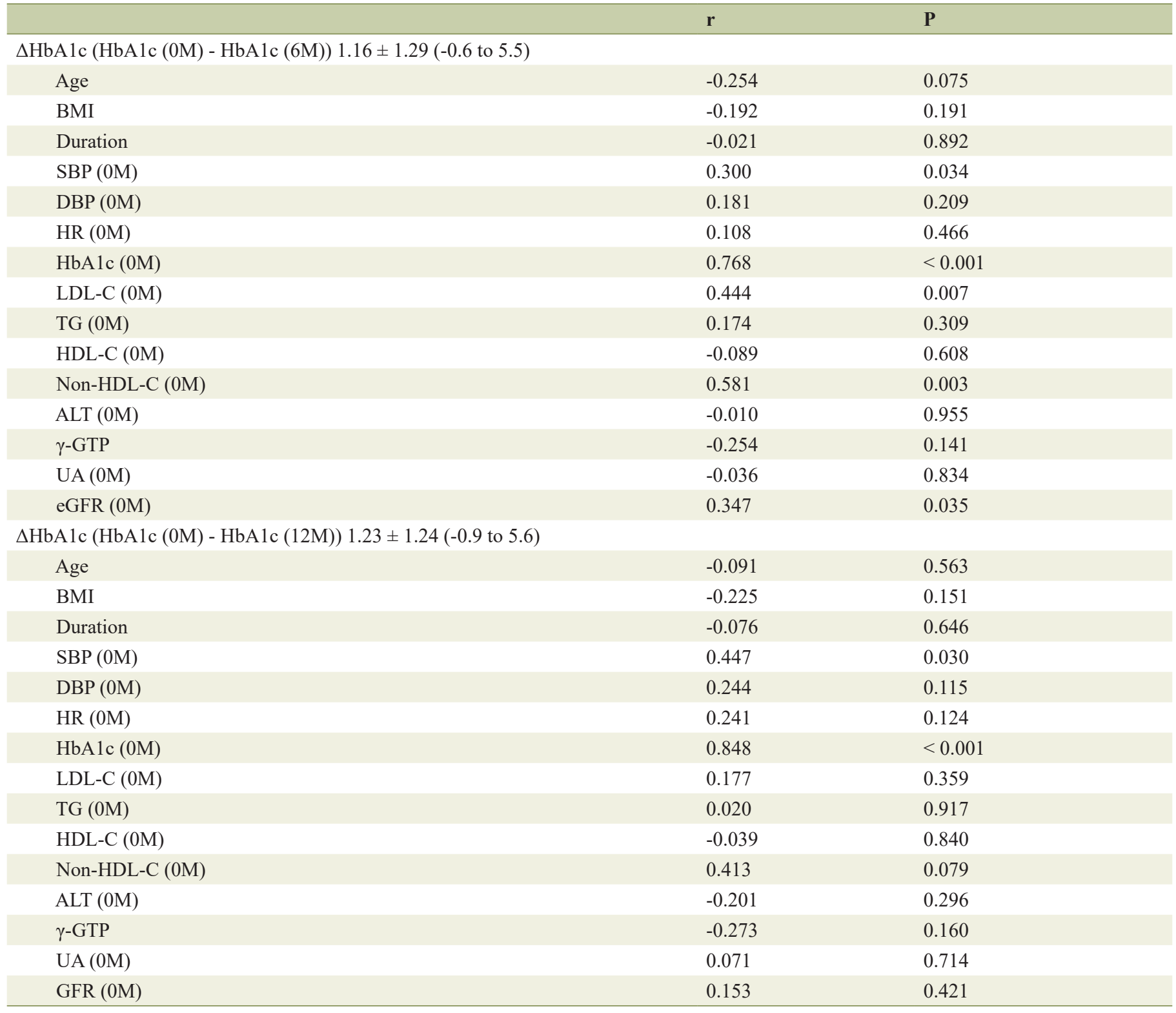

BMI: body mass index; SBP: systolic blood pressure; DBP: diastolic blood pressure; HR: heart rate; HbA1c: hemoglobin A1c; LDL-C: low-density lipoprotein cholesterol; TG: triglyceride; HDL-C: high-density lipoprotein cholesterol; ALT: alanine transaminase; $\gamma$-GTP: gamma-glutamyl transpeptidase; UA: uric acid; eGFR: estimated glomerular filtration rate; 0M: 0 months (baseline); 6M: after 6 months of treatment; $12 \mathrm{M}$ : after 12 months of treatment.

Table 5. Correlations of $\mathrm{HbA} 1 \mathrm{c} 0 \mathrm{M}$ With $\triangle \mathrm{HbA} 1 \mathrm{c}$ (After Adjusting for SBP 0M) and SBP With $\triangle \mathrm{HbA} 1 \mathrm{c}$ (After Adjusting for $\mathrm{HbA} 1 \mathrm{c} 0 \mathrm{M}$ )

\begin{tabular}{|c|c|c|}
\hline & $\mathbf{r}$ & $\mathbf{P}$ \\
\hline \multicolumn{3}{|c|}{$\Delta \mathrm{HbA} 1 \mathrm{c}(\mathrm{HbA} 1 \mathrm{c}(0 \mathrm{M})-\mathrm{HbA} 1 \mathrm{c}(6 \mathrm{M})) 1.16 \pm 1.29(-0.6$ to 5.5$)$} \\
\hline $\operatorname{HbAlc}(0 \mathrm{M})$ & 0.743 & $<0.01$ \\
\hline \multicolumn{3}{|c|}{$\Delta \mathrm{HbA} 1 \mathrm{c}(\mathrm{HbA} 1 \mathrm{c}(0 \mathrm{M})-\mathrm{HbA} 1 \mathrm{c}(12 \mathrm{M})) 1.23 \pm 1.24(-0.9$ to 5.6$)$} \\
\hline $\mathrm{HbA1c}(0 \mathrm{M})$ & 0.810 & $<0.01$ \\
\hline
\end{tabular}

HbA1c: hemoglobin A1c; SBP: systolic blood pressure; 0M: 0 months (baseline); 6M: after 6 months of treatment; $12 \mathrm{M}$ : after 12 months of treatment. 
leading to hypertension. Previously reported anti-hypertensive mechanisms of DDP-4 inhibitors include prolongation of the effects of natriuretic hormones such as atrial natriuretic peptide (ANP) and B-type natriuretic peptide (BNP) [15, 16], suppression of the action of the proximal tubular $\mathrm{Na} / \mathrm{H}$ antiporter via GLP-1 receptors and the resulting induction of natriuresis [17] and vascular smooth muscle relaxation action [18].

Blood pressure, obesity, LDL-C and triglycerides are risk factors for macroangiopathy. Moreover, the onset of macroangiopathy is known to increase as the number of these risk factors increases. The present study suggests the potential of alogliptin as a comprehensively useful drug, not only in terms of blood glucose values but also for managing blood pressure, body weight, and lipids. Although recent studies report an improvement in the short-term prognosis of cardiovascular diseases with sodium-glucose cotransporter-2 (SGLT2) inhibitors $[19,20]$, there are no data showing improvement of short-term prognosis by DPP-4 inhibitors. In the present study, the effect of alogliptin treatment on multiple outcomes supports the possibility that the long-term administration of alogliptin could prevent macrovascular disease.

\section{Study limitation}

Although the present study used a prospective design, it was conducted in a single cohort with no control group. Thus, further studies using a prospective placebo comparison design are needed.

There was the lack of pre-assumption regarding data for alcohol drinking and physical activity using a questionnaire survey in this study. Each of the participated doctors in this study gave lifestyle guidance, independently, so that the details of lifestyle modification in each patient were not determined. This point was one of the limitations for discussing the results of reduced blood pressure, body weight, or lipid profiles.

\section{Conclusion}

We conducted a prospective, interventional observational study on alogliptin targeting community-based individuals and confirmed the efficacy and safety of alogliptin when used in a real-world clinical setting. Our findings show that individuals with high baseline HbA1c tend to show effects more easily. Additionally, alogliptin reduced body weight and improved blood pressure. Alogliptin is a useful diabetic drug not only for blood glucose control but also for controlling body weight and blood pressure.

\section{Acknowledgments}

We thank Mrs. Nao Totake for her excellent technical assistance. We also thank the following members of the Chikushi Cardiovascular Research Network for recruiting participants for this study: Yoshihiro Tsuchiya (Ohashi Internal Medicine and Cardiovascular Clinic), Kimishige Imoto (Imoto Clinic), Kazuyuki
Takata (Takata Medical Clinic), Yoshiaki Utsunomiya (Utsunomiya Medical Clinic), Masanori Shimizu (Shimizu Clinic), Teiichi Miyauchi (Miyauchi Iin), Yohichi Tanabe (Tanabe Clinic), Yoichi Tsuruta (Tsuruta Clinic), Yasuo Tomita (Tomita Clinic), Yuichiro Nakamura (Nakamura Cardiovascular Clinic), Tomoko Hyodo (Kitajima Clinic), Hiroyasu Kusaba (Imamura Hospital), Tadasu Matsuzaki (Matsuzaki Clinic), Shunji Miake (Sugi Hospital), Masahiko Mohri (Mori Geka), Kenzo Matsumoto (Seiwa Memorial Hospital), Kei Miyoshi (Asagi Hospital), Hiroshi Ninomiya (Chikushiminamigaoka Hospital A Medical Corporation), Hirofumi Sameshima (Tohoku Sameshima Clinic), Toshiaki Kadokami (Fukuokaken Saiseikai Futsukaichi Hospital), Keiichi Midorikawa (Midorikawa Naikajunkankika Iin), Kunihisa Gondo (Gondo Internal Medicine Clinic), Ken Kitajima (Fukuoka University Chikushi Hospital), Shunichiro Sumi (Fukuoka University Chikushi Hospital), Takehiro Kodera (Fukuoka University Chikushi Hospital) and Ken Mori (Fukuoka University Chikushi Hospital).

\section{Financial Disclosure}

The authors have received financial support from Takeda Pharmaceutical Company Limited (110304FK).

\section{Conflict of Interest}

The authors declare no conflict of interest.

\section{Informed Consent}

The protocol of this study included a predetermined informed consent process for each patient, which was followed as described in the application document of the above-mentioned ethics committee, and written informed consent was obtained from each patient.

\section{Author Contributions}

YT performed research including data collection and analysis, and wrote the paper. TK performed research including data collection and participated discussion. KK and HU designed the study and edited the manuscript. All authors have approved the final version to be published.

\section{Data Availability}

The authors declare that data supporting the findings of this study are available within the article.

\section{References}

1. Intensive blood-glucose control with sulphonylureas or 
insulin compared with conventional treatment and risk of complications in patients with type 2 diabetes (UKPDS 33). UK Prospective Diabetes Study (UKPDS) Group. Lancet. 1998;352(9131):837-853.

2. Holman RR, Paul SK, Bethel MA, Matthews DR, Neil HA. 10-year follow-up of intensive glucose control in type 2 diabetes. N Engl J Med. 2008;359(15):1577-1589.

3. Duckworth W, Abraira C, Moritz T, Reda D, Emanuele N, Reaven PD, Zieve FJ, et al. Glucose control and vascular complications in veterans with type 2 diabetes. N Engl J Med. 2009;360(2):129-139.

4. Shichiri M, Kishikawa H, Ohkubo Y, Wake N. Longterm results of the Kumamoto Study on optimal diabetes control in type 2 diabetic patients. Diabetes Care. 2000;23(Suppl 2):B21-29.

5. Nomiyama T, Akehi Y, Takenoshita H, Nagaishi R, Terawaki Y, Nagasako H, Kudo T, et al. Contributing factors related to efficacy of the dipeptidyl peptidase- 4 inhibitor sitagliptin in Japanese patients with type 2 diabetes. Diabetes Res Clin Pract. 2012;95(2):e27-28.

6. Takamiya Y, Okamura K, Shirai K, Okuda T, Kobayashi K, Urata H. Multicenter prospective observational study of teneligliptin, a selective dipeptidyl peptidase-4 inhibitor, in patients with poorly controlled type 2 diabetes: Focus on glycemic control, hypotensive effect, and safety Chikushi Anti-Diabetes Mellitus Trial-Teneligliptin (CHAT-T). Clin Exp Hypertens. 2020;42(3):197-204.

7. Esposito K, Chiodini P, Capuano A, Maiorino MI, Bellastella $\mathrm{G}$, Giugliano D. Baseline glycemic parameters predict the hemoglobin A1c response to DPP-4 inhibitors : meta-regression analysis of 78 randomized controlled trials with 20,053 patients. Endocrine. 2014;46(1):43-51.

8. Kim YG, Hahn S, Oh TJ, Kwak SH, Park KS, Cho YM. Differences in the glucose-lowering efficacy of dipeptidyl peptidase-4 inhibitors between Asians and non-Asians: a systematic review and meta-analysis. Diabetologia. 2013;56(4):696-708.

9. Feng J, Zhang Z, Wallace MB, Stafford JA, Kaldor SW, Kassel DB, Navre M, et al. Discovery of alogliptin: a potent, selective, bioavailable, and efficacious inhibitor of dipeptidyl peptidase IV. J Med Chem. 2007;50(10):22972300.

10. Monnier L, Lapinski H, Colette C. Contributions of fast- ing and postprandial plasma glucose increments to the overall diurnal hyperglycemia of type 2 diabetic patients: variations with increasing levels of $\mathrm{HbA}(1 \mathrm{c})$. Diabetes Care. 2003;26(3):881-885.

11. Shah Z, Kampfrath T, Deiuliis JA, Zhong J, Pineda C, Ying $\mathrm{Z}, \mathrm{Xu} \mathrm{X}$, et al. Long-term dipeptidyl-peptidase 4 inhibition reduces atherosclerosis and inflammation via effects on monocyte recruitment and chemotaxis. Circulation. 2011;124(21):2338-2349.

12. Monami M, Lamanna C, Desideri CM, Mannucci E. DPP-4 inhibitors and lipids: systematic review and metaanalysis. Adv Ther. 2012;29(1):14-25.

13. Eliasson B, Moller-Goede D, Eeg-Olofsson K, Wilson C, Cederholm J, Fleck P, Diamant M, et al. Lowering of postprandial lipids in individuals with type 2 diabetes treated with alogliptin and/or pioglitazone: a randomised double-blind placebo-controlled study. Diabetologia. 2012;55(4):915-925.

14. Iimura O. Insulin resistance and hypertension in Japanese. Hypertens Res. 1996;19(Suppl 1):S1-8.

15. Kim M, Platt MJ, Shibasaki T, Quaggin SE, Backx PH, Seino S, Simpson JA, et al. GLP-1 receptor activation and Epac2 link atrial natriuretic peptide secretion to control of blood pressure. Nat Med. 2013;19(5):567-575.

16. Tanaka T, Nangaku M, Nishiyama A. The role of incretins in salt-sensitive hypertension: the potential use of dipeptidyl peptidase-IV inhibitors. Curr Opin Nephrol Hypertens. 2011;20(5):476-481.

17. Crajoinas RO, Oricchio FT, Pessoa TD, Pacheco BP, Lessa LM, Malnic G, Girardi AC. Mechanisms mediating the diuretic and natriuretic actions of the incretin hormone glucagon-like peptide-1. Am J Physiol Renal Physiol. 2011;301(2):F355-363.

18. Makino Y, Fujita Y, Haneda M. Dipeptidyl peptidase-4 inhibitors in progressive kidney disease. Curr Opin Nephrol Hypertens. 2015;24(1):67-73.

19. Zinman B, Wanner C, Lachin JM, Fitchett D, Bluhmki E, Hantel S, Mattheus M, et al. Empagliflozin, cardiovascular outcomes, and mortality in type 2 diabetes. N Engl J Med. 2015;373(22):2117-2128.

20. Baglioni P. Canagliflozin and cardiovascular and renal events in type 2 diabetes. N Engl J Med. 2017;377(21):2097-2098. 